\title{
Complementarity and Demand Theory: From the 1920s to the 1940s
}

\author{
Jean-Sébastien Lenfant
}

The history of consumer demand is often presented as the history of the transformation of the simple Marshallian device into a powerful Hicksian representation of demand. Once upon a time, it is said, the Marshallian "law of demand" encountered the principle of ordinalism and was progressively transformed by it into a beautiful theory of demand with all the attributes of modern science. The story may be recounted in many different ways, introducing small variants and a comparative complexity. And in a sense that story would certainly capture much of what happened. But a scholar may also have legitimate reservations about it, because it takes for granted that all the protagonists agreed on the meaning of such a thing as ordinalism - and accordingly that they shared the same view as to what demand theory should be. On the contrary, it may well be more accurate to think that ordinalism was as much a product of the story as it was a principle leading the intellectual change.

Thus it may be useful to hypothesize that what happened to the theory of the rational consumer and to demand theory in the first half of the twentieth century is the consequence of a rising interest attached to the idea of choice among alternatives. Consequently, it might be more accurate to think that demand theory and ordinalism went hand in hand at

This article has benefited from comments by participants at the 2005 HOPE conference. I am also indebted to Philippe Mongin and Wade Hands for criticism, insights, and encouragements on previous versions. All remaining errors are my own.

History of Political Economy 38:5 DOI 10.1215/00182702-2005-017

Copyright 2006 by Duke University Press 
least until the late 1930s. This story may be traced back to F. Y. Edgeworth, Vilfredo Pareto, and Irving Fisher, who introduced indifference curves into the microeconomics of consumption and exchange. Introducing choice into microeconomic theory opened the door to new questions and to the need for new tools of analysis as well as to a profound transformation of the representation of the psychological foundations of choice and demand theories. It led eventually to the now-standard theory of the consumer, after John R. Hicks's and Eugen Slutsky's contributions. The new Hicksian theory of demand that was "stabilized" in the 1940s was the result of debates on many related issues: What kinds of tools were needed to study demand and choice? What methodological principles should be adopted for this? Is choice to be rationalized by some kind of psychological explanation? Is rationality worth testing?

Some light may be shed on the transformations of demand analysis in the 1930 s by telling the story of one of the period's most debated concepts: complementarity. What is the meaning of such sentences as " $x$ and $y$ are substitutes," " $y$ and $z$ are complementary goods," or " $x$ and $z$ are independent"? If $x$ is a substitute for $y$, will $y$ necessarily be a substitute for $x$ ? Is it supposed to have any empirical counterpart? What kind of meaning does it have in the first place? ${ }^{1}$ All those questions emerged soon after the marginalist revolution and were given prominence in the 1930s. They were at the center of the reshaping of demand theory, toward the now-classic Hicks-Slutsky presentation of demand theory.

The purpose of the present article is to focus on how economists debated the need for a "good" concept of complementarity and how they eventually adopted a definition that fit the needs of both econometric modeling and a theory of market interdependencies. Indeed, the reshaping of demand theory in the thirties was stimulated by statistical studies of demand, and econometrics played a prominent role in stabilizing neoclassical demand theory in the early forties.

The first section summarizes the history of complementarity up to Slutsky and gives an overview of the theoretical and methodological context of the 1920s that fostered a renewed interest in the concept of complementarity. The second section captures the ins and outs of Hicks and Roy Allen's 1934 reconstruction of demand and complementarity. The third section deals with parallel developments on the concept of related goods

1. Of course, it is clear from those questions that complementarity is used here as a generic word to represent the relations between goods. 
that were conducted by Harold Hotelling and Henry Schultz in the early thirties and provides a narrative about stabilizing demand theory in the late thirties through Hicks's synthesis.

\section{A Renewed Interest in Complementarity}

Complementarity has been a subject of interest in the context of the marginalist revolution with the development of a Paretian theory of choice. It was then largely ignored under Marshallian dominance and was to be rehabilitated as an important question through the development of early econometrics in the 1920s. In this section, I briefly narrate how the concept was first developed at the turn of the twentieth century and how it became anew a subject of interest. ${ }^{2}$

Complementarity before the 1920 s

The first commonly accepted definition of completing and competing goods was proposed by Rudolf Auspitz and Richard Lieben ([1889] 1914) and was later adopted by Edgeworth, Pareto, and Fisher. It was so quickly adopted because it was a quite natural way to interpret the cross second-order derivative of the utility function. The ALEP definition (from Auspitz, Lieben, Edgeworth, and Pareto) did not emerge as the result of long reflection but rather as a word given to an introspectively felt relation between goods: the analytic expression $\partial^{2} u(.) / \partial x \partial y$ preceded the definition. ${ }^{3}$

From William Stanley Jevons [1871] 1965 onward, it would certainly be difficult to find a writer interested in price and demand theory who does not devote some pages to the notions of substitutes and complements. The

2. For a wider and more detailed study, see Lenfant 2003. Some other aspects of the story have been studied in Chipman and Lenfant 2002.

3. This definition was introduced in a discussion of the shape of a so-called pleasure function (Lebensgenusskurve). While studying the sign of this function, Auspitz and Lieben had to cope with the second derivative of another function $\phi\left(x_{1}, x_{1}\left(x_{1}\right), \ldots, x_{n}\left(x_{1}\right)\right)$, and thus discussed the sign of a sum of terms

$$
\frac{\partial^{2} \phi(\cdot)}{\partial x_{i} \partial x_{1}} \frac{\partial x_{i}}{\partial x_{1}} .
$$

On this occasion, Auspitz and Lieben introduced their famous criterion of complementarity. The cross second-order derivatives $\left(\partial^{2} \phi(\cdot) / \partial x_{1} \partial x_{i}\right)_{i \geq 2}$ will be positive, zero, or negative "depending on whether $\left(x_{\mathrm{i}}\right)$ is a complement to the enjoyment of $\left(x_{1}\right)$, is totally indifferent to $\left(x_{1}\right)$, or is competing to it"(Auspitz and Lieben [1889] 1914, 319). 
first approach to the definition of complementarity is based on utility-and there every economist accepts the ALEP criterion. A second approachpacifically cohabitating with the first one-is built on preferences and indifference curves. Both approaches aim at improving demand theory. Thus complementarity has been linked with demand analysis from the outset, especially with the study of related demand..$^{4}$ It was commonly accepted that a price rise would eventually diminish the consumption of complementary goods. The ALEP criterion led one to question this intuitive statement, and Auspitz and Lieben ([1889] 1914, 98) were the first to mention-without any formal proof, however-that the properties of utility could disturb this law of related demand:

It is nevertheless possible that some opposite manifestations may occur, because of the many cross-linked influences between goods. Thus, a rise in the consumption of coffee will always result in an increase in the quantity of sugar used to sweeten it, but, if the same individual is also reducing his consumption of tea in consequence of an increased use for coffee, it may happen that, instead of increasing, its total consumption of sugar should diminish.

A next step in the history of complementarity is Pareto's Manual of Political Economy (in the fourth chapter, "Tastes"). Here Pareto undertakes a thorough analysis of utility, preferences, and tastes and tackles the subject of substitutes and complements in consumption. This study dramatically changes the meaning of complementarity for value theory. With Pareto, complementarity becomes a concept for the theory of choice. As did Fisher, Pareto ([1909] 1971, 182, sec. 8) deals with complementarity when introducing a generalized utility function, and he adopts Auspitz and Lieben's analytic definition (Pareto [1909] 1971, appendix, sec. 46, equations 63, 64). Pareto's discussion reveals that he did not think that the concept of complementarity exhausted all the introspective and mental states of the mind for the description of choice situations, and that it should better be used as a first approximation, an imperfect analytic representation of our states of minds as consumers.

4. But it would be misleading to believe that it has always been the sole or even the main reason for developing the concept of complementarity. Alfred Marshall [1890] 1898, Auspitz and Lieben [1889] 1914, and Fisher [1892] 1961 will make special uses of the concept (in explaining the properties of the price system or in justifying a measure for consumer surplus). Moreover, as regards demand theory properly, complementarity appeared both in the study of related demands and in the study of the law of demand. 
It is well known that both Fisher and Pareto were reluctant to accept psychological arguments in economics (although maybe not to the same extent). This meant, in the first place, to break with the traditional reference to utility as a measuring rod for pain and pleasure and, more broadly, to break with the search for ultimate causes (Fisher [1892] 1961, 5; Pareto [1909] 1971, 160). For that reason, both of them engaged in another discussion about complementarity, on the basis of indifference curves. To that extent, their work is more representative of a preference-based approach to complementarity. ${ }^{5}$ For all that, the preference-based approach is not presented as breaking away from the utility-based approach but rather as another way to look at demand behavior.

Fisher's typology is well known. In his Investigations, he endeavored to match the preference-based definition-a general typology built on different shapes of indifference curves - and properties of the price system. ${ }^{6}$ Following on this line of thought, Pareto inaugurated a far more sophisticated analysis of complementarity. ${ }^{7} \mathrm{He}$ went beyond merely discussing the shape of indifference curves to describe the properties of the indifference map. Through this analysis, Pareto sought to explain the occurrence of increasing demand. Thus his main contribution was to shift the analysis of complementarity by giving up the study of the shape of single indifference curves and focusing instead on the shape of indifference maps. Simultaneously, Pareto shifted from the analysis of related demand to the analysis of the law of demand.

5. Compare the presentation in the full text of the Manual with the one in the appendix (secs. 44-51).

6. This approach is based on the idea that, within a two-good framework, complementarity relations can be made apparent and classified through a study of the curvature of indifference curves. Actually, Fisher does not develop this idea or any tools for differentiating substitutes and complements. The point is rather that Fisher is not interested in complementarity in itself; his idea is to create a continuous geometrical typology and to implement this representation in price theory. To that extent, Fisher makes a rather straight instrumental use of the concept, and he does not even pretend to discuss his own typology in relation with the ALEP criterion. He simply uses it to illustrate some statements about the properties of the price system: "The essential quality of substitutes or competing articles is that the marginal utilities or the prices of the quantities actually produced and consumed tend to maintain a constant ratio. We may define perfect substitutes as such that this ratio is absolutely constant. The essential attribute of completing articles is that the ratio of the quantities actually produced and consumed tends to be constant (as many shoe-strings as shoes for instance, irrespective of cost). We may define perfect completing articles as such that this ratio is absolutely constant" (Fisher [1892] 1961, 66; emphasis in original).

7. That Pareto investigates both the utility-based and the preference-based approach to complementarity accords with his ecumenical methodology. The choice of one method over the other is a question of convenience and circumstances. 
To put it briefly, it is well known that Pareto came most of the way in deriving the Slutsky equation in the October 1893 issue of the Giornale degli economisti (Chipman 1976; Dooley 1983; Weber 1999). In theorizing about demand, Pareto gave the era's most general expression on the effect of a price change on the demand for a good. As a comment to this expression (equation 75 in Pareto [1909] 1971, 423), Pareto underlined the possible implications of ALEP complementarity, but he also remarked that this criterion cannot by itself serve as a basis for the law of demand, except in the case of complementary or independent goods: "For goods having a dependence of the second type [ALEP substitutes], when the price rises, the demand may increase and then decrease" (197-98). According to this lack of empirical implications of complementarity, Pareto shows that it is not easy to develop a solid basis for demand theory without having recourse to something other than complementarity in the ALEP sense (199).

In sum, Pareto's contribution to demand theory is inseparable from his reflection on complementarity. On the one hand, he lays down the empirical implications of the ALEP criterion; on the other, he tackles semantic aspects of the concept, in particular in relation with the ALEP criterion. One is even led to the result that the search for a new definition of substitutes and complements (following the preference-based approach) did not originate in any desire to give up the cardinalist criterion but was motivated by the search for a more precise and powerful theory of demand.

William Johnson (1913) was the first to provide an ordinal definition of complementarity on the basis of the derivatives of the marginal rate of substitution (although he does not use the name) and to show that this definition cannot easily be compared with the traditional ALEP criterion. ${ }^{8}$ Johnson's systematic recasting of the concept leads to integrating the utility-based approach within the preference-based approach. In this respect, his typology of complements and substitutes is even more dedicated toward laying the foundations for a new theory of demand.

The final step in this early story of complementarity is Slutsky's 1915 contribution. It is rather difficult to classify. Slutsky does not elaborate on the preference-based approach, and to that extent he is not developing the Fisher-Pareto-Johnson line of thought. Instead, he focuses exclusively on the relationships between the ALEP criterion and demand behavior.

8. See Schultz 1938, Stigler [1950] 1965, Samuelson 1974, Newman 1987. 
Slutsky's famous equation-the first analytic decomposition between income and substitution effects - gives the variation in the demand of a good in reaction to a variation of the price of another good. In modern notation: ${ }^{9}$

$$
\frac{\partial x_{i}(p, R)}{\partial p_{j}}=s_{i, j}(p, R)-x_{j}(p, R) \frac{\partial x_{i}(p, R)}{\partial R}
$$

Slutsky ([1915] 1953, eq. 55) also derived the following symmetry "condition":

$$
s_{i j}=\frac{\partial x_{j}}{\partial p_{i}}+x_{i} \frac{\partial x_{j}}{\partial R}=\frac{\partial x_{i}}{\partial p_{j}}+x_{j} \frac{\partial x_{i}}{\partial R}=s_{j i}
$$

Actually, $s_{i j}$ is the "residual variability" of the $j^{\text {th }}$ good for a "compensated variation" of the price $p_{i}$ (Slutsky [1915] 1953, 43), that is, for a variation of income that allows the consumer to buy exactly the same bundle as before.

Moreover, on the basis of the above results, Slutsky wonders about the empirical counterpart of the second derivatives of the utility function. He comes to a negative conclusion, which is of direct consequence for distinguishing between complementary and competitive goods. Indeed, Slutsky provides the first explicit challenge to the ALEP criterion. ${ }^{10} \mathrm{His}$ conclusion is a final judgment: "This whole edifice falls if one remains loyal to the formal definition of utility, for it is impossible to deduce from the facts of behavior the character (that is, the sign) of the second derivative of utility" (54). ${ }^{11}$

As a brief summary of this sketchy early history of the concept of complementarity, one can see that complementarity was the object of more or less parallel investigations on the part of Fisher, Pareto, Johnson, and Slutsky. All of them had the ALEP criterion in mind and tried either to trace its limits or to complete it with an analysis of indifference curves. Pareto is the one who shifted the conceptualization of complementarity

9. Where $x_{i}$ is the quantity demanded of commodity $i, p_{j}$ is the price of commodity $j$, and $R$ is income, while $s_{i, j}$ is the Slutsky substitution effect, representing the differential change in the consumption of $i$ when the differential change of $p_{j}$ is compensated so that consumers can still just afford their original consumption bundles.

10. Of course, Pareto showed that the ALEP criterion is not self-sufficient to have clear-cut implications on demand behavior. For all that, he did not mean explicitly that the converse was true, that is, that demand behavior could not deliver some information about complementarity in the ALEP sense, at least on the basis of global information on prices and quantities bought.

11. For an appraisal of Slutsky's interest in complementarity, see Lenfant 2003. 
by emphasizing the theory of choice, and Slutsky completed the move. Despite these differences, their reflections on complementarity share a common feature: the concept is regarded as a two-good relation. This is precisely this common horizon that would progressively collapse in the next twenty years. Also, it is remarkable that the complex relations between utility, demand, and preferences opened the door to many different lines of thought in developing the theory of demand and in connecting it with complementarity. As a result, in the 1920s and early 1930s, economists did not have a satisfactory definition of complementarity.

Taking Complementarity Seriously in the 1920s and Early 1930s

Under the influence of the early econometricians, the interest in complementarity was widespread among economists of the 1920s and 1930s, and the Hicks and Allen contributions (especially Hicks and Allen 1934) to the theory of value constituted the acme of the work on complementarity.

The great difference in the history of the ALEP definition that I have just recounted lies in the fact that the need for a new definition of complementarity preceded the definition itself and that no definition seemed to apply naturally. From this moment on, something was on track for a complete reshaping of demand theory along the lines of Pareto and Fisher. One reason for this was the growing interest in the 1920s in the Lausanne school in England and the United States. In addition, Marshallian ideas on supply, demand, and surplus were subjected to increasing criticism as statistical economists and early econometricians played a growing role in the development of economics. ${ }^{12}$

The idea that competitive goods and complementary goods should be taken into account in the statistical analysis of demand was already at stake at the very beginning of the twentieth century. In 1907 Rudolfo Benini had expressed the demand for coffee in Italy as a function of the prices of coffee and sugar, using the method of multiple correlation. In the 1920s, estimations of demand functions for agricultural products sometimes incorporated complementary and competitive goods. But it is remarkable that complementarity was never a subject of serious speculation but only a way to implement new statistical tools. None of the main studies of demand reflect on the best way to integrate substitutes and complements

12. On this question, see Stigler 1954, Christ 1985, and Morgan 1990. 
or even address how to know if a good should be counted as a substitute or as a complement. ${ }^{13}$

Things would change radically in the years 1930-33. The recognition of a need for proper reflection on complementarity was progressively fostered by econometricians such as Mordecai Ezekiel, W. F. Ferger, and Elisabeth Waterman Gilboy, and by economists at the frontier between statistical analysis and pure economic theory, such as Marco Fanno and Paul N. Rosenstein-Rodan. ${ }^{14}$ They pointed out that (1) it was necessary to identify competitive and complementary goods and to neutralize their influences on the demand for a good if one aims at measuring elasticity of demand; and (2) the way to introduce related goods within the statistical studies on demand is not self-evident. Which related good should be retained in the estimation? What method should be privileged for this purpose? What would be the theory underlying the methods? Answering those questions soon appeared as a requisite for developing statistical studies of demand.

It is quite probable that the critical assessment of Henry Moore's rising demand for pig iron in Economic Cycles ([1914] 1967) was a starting point for all this. Moore's results were criticized not only for a kind of lack of rigor or patience with statistical methodology but also for his conception of demand that was at odds with the Marshallian law of demand and uninterested in a fruitful cooperation between theoretical economics and statistical economics (Working 1927; Lehfeldt 1915). Thus R. A. Lehfeldt (1915, 410-11) pointed out that Moore had estimated something that was "much more nearly a supply curve." Those critical assessments are known to be the point of departure of the identification problem in econometrics. But they also show that early statistical economists strongly disagreed on the role and the place of statistical economics and on the purpose of statistical demand studies. Was it to estimate something else than the Marshallian demand curve? Was it to pursue the never-ending goal of estimating it? Ferger $(1932,36)$ would sum up this

13. Even Schultz, who was to champion integrating choice analysis and statistical laws of demand, did not consider that complementary and competitive goods were instrumentally useful for computing statistical laws of demand. In The Statistical Laws of Demand and Supply, with Special Application to Sugar (1928b), he introduced the price of different goods together with a temporal variable and eventually eliminated those other goods from the regression, considering that the temporal variable should represent all the variations.

14. See also Ezekiel's bibliography $(1933,172)$. The most important articles for the present story, leaving Schultz aside, are Fanno 1926, 1929, 1933; Ferger 1932; Gilboy 1930, 1932, 1934; Ezekiel 1927, 1933; Wright 1929, 1930; Lehfeldt 1914, 1915; and Rosenstein-Rodan 1933. 
"great disagreement regarding the concepts involved" in statistical demand curves. He notes that "in none of the methods thus far considered has the fundamental condition of the classical definition of static demand curves been realized-that all other things remain unchanged" (59; emphasis in original). In the same vein, in 1933, Ezekiel could still regret that "in spite of the general recognition of the importance of competing products, no one appears as yet to have attempted to formulate clearly the exact way in which they enter into the demand situation, or to determine on a logical basis which is the best way to bring them into the statistical investigation" (173).

In the first issue of Econometrica, Fanno underlined the technical difficulties raised by the study of the influence of a good's price on the demand for another good. To study the relationships between prices and quantities of substitutes requires accounting "for the simultaneous variations of the prices of all the goods within the group" (Fanno 1933, 165). Thus it is necessary to integrate interdependence in the statistical regressions and also to know how to select those related goods that are supposed to enter into the regression. Practically, the econometrician has to restrain the number of goods related by "direct economic relationships" (162). Ezekiel echoes Fanno's recommendations by comparing two models of interrelated demand. In the first model, $p_{1}$ is explained by $x_{1}$ and $x_{2}$, whereas in the second model $p_{1}$ is explained by $x_{1}$ and $p_{2}$ (and symmetrically for $p_{2}$ ):

$$
\begin{gathered}
\left\{\begin{array}{l}
p_{1}=h_{1}\left(x_{1}, x_{2}\right) \\
p_{2}=h_{2}\left(x_{1}, x_{2}\right)
\end{array}\right. \\
\left\{\begin{array}{l}
p_{1}=H_{1}\left(x_{1}, p_{2}\right) \\
p_{2}=H_{2}\left(x_{2}, p_{1}\right)
\end{array}\right.
\end{gathered}
$$

Ezekiel mixed theoretical and statistical arguments in favor of the first model and against the second. The choice of one model over the other may first depend on a hypothesis about the reactivity of one market. In this case, the second model may be favored. But the second model is flawed by its circularity, the price of each good being explained partly by itself (Ezekiel 1933, 178).

Thus, at the beginning of the thirties, the early econometrists of demand (especially in agricultural economics) show an urgent interest for a theory of related demand, but the theoretical and statistical methods for it are still in the wings or, at best, too controversial. Around 1933, the time was ripe 
for a fruitful dialogue between the pure theory of choice and the statistical analysis of demand in order to provide a useful definition of complementarity and substitution. Any theory that may help communicate the impact of the price of a good on the demand for another would be welcome for estimating statistical demand curves. Henry Schultz would be the one to develop this connection. What remains to be understood is to what extent those early econometrists thought it useful to support their analyses with the Paretian theory of choice as it existed at the time.

\section{From Moore to Schultz}

The relationship between statistical economics and pure economics and how it evolved is best perceptible through the writings of Henry Moore and Henry Schultz on demand studies. ${ }^{15}$ There we can find the justification for developing statistical economics on the basis of pure mathematical economics. Among the American economists, Moore and Schultz shared a good knowledge of Léon Walras and Pareto, and the former were convinced that general equilibrium was the only solid basis for doing economics. ${ }^{16}$ But to Moore, it deserved to be completed and criticized for its static nature. Already in Economic Cycles and later in Forecasting the Yield and the Price of Cotton ([1917] 1967), Moore would clarify the way statistical economics should account for interdependencies between markets.

To put it briefly, Moore's aim in Economic Cycles is to establish a chain of causality between "the law of the cycles of rainfall" and "the law of the cycles of the crops," on the one side, and "the law of Economic Cycles," on the other ([1914] 1967, 135). The statistical relation between the demand for agricultural products and the price of agricultural products is presented as a propagation mechanism for cycles, and Moore devotes chapter 4 to the analysis of demand. ${ }^{17}$ Moore's economics relies on supposedly natural laws whose perception is made difficult because of endless cycles and changes. Further, those natural laws are in essence dynamic and need technical abilities to be discovered. The dynamic law of demand, in Moore's mind, must take into account both

15. In 1916 Schultz began to study under Moore at Columbia. After the war, he was at the LSE, studying under Arthur L. Bowley and Karl Pearson. He came back to Columbia for his PhD in 1925 (Mirowski 1990, 605).

16. See Moore 1929; Schultz 1927, 1928a.

17. On Moore and demand, more generally, see Wulwick 1995. 
the interdependencies of demands (and markets) and the unavoidable temporal character of all laws in economics. Instead of "an idol of the static state," Moore wishes to obtain statistical equations by "attacking directly the problem in its full concreteness," "other things changing according to their natural order," thus providing the "Statistical Complement to Deductive Economics" $(64,66,67)$.

Although Moore attached great importance to Pareto's and Walras's expositions of the economic system, he did not praise them for the utility foundations of it and, more generally, for the static representation of the equilibrium based on a mechanical metaphor. For this reason, he wanted to go beyond putative explanations of economic phenomena through a theory of utility and a mechanical representation of it (Moore [1914] 1967, 85). In return, he maintained the principle of interdependence of markets. As a result, substitutability, once disentangled from any a priori and rationalist foundation, is seen as a main cause of endless theoretical difficulties that would be overcome only through the search for dynamical laws of demand:

In treatises on pure economics, particularly in those in which mathematical analysis is employed, the masters of the a priori method [i.e., mathematical economists using general equilibrium] point out what they regard as the extreme difficulty of the actual problem of the relation of price to quantity of commodity - a difficulty growing out of the interrelation of the many factors in the problem. . . The degree in which hay, oats, and potatoes are substituted for corn is dependent not only upon the price of corn but also on their own several prices, and these latter prices are, in turn, dependent upon the supply and price of corn! This statement of the problem, complex as it appears, is unduly simplified; and it is presented not in order to ridicule the work of the masters who have elaborated the method of stating the problem in the form of simultaneous equations, but to show how hopelessly remote from reality is the very best theoretical treatment of the problem of the relation of price to the quantity of commodity, and to suggest, from the results of the preceding pages of this chapter, how imaginary, theoretical difficulties are dispelled by solving real problems. (82)

Moore's theoretical and technical apparatus is thus presented as a solution to endless theoretical disputes in pure economics. All the complex relationships that are never tested become of secondary order or even null and void once we calculate a simpler relation on the whole economic cycle. 
Calculating the elasticity of demand for a representative good over a sufficiently long period and using the method of multiple correlation gives "an extremely accurate formula summarizing the relation between variations in price and variations in the amount of the commodity that is demanded" (70). ${ }^{18}$

It is commonly accepted that Moore had no great influence on other econometricians except for Schultz. But it is also known that Schultz was not a faithful follower of Moore. ${ }^{19}$ The fascinating point is that Schultz tended to extirpate demand analysis from Moore's general project and methodology and to interpret it as an independent given that may still be improved; all subsequent works by Schultz on demand can be interpreted as implementing this program. On this occasion, Schultz gave central importance to utility theory for the statistical analysis of demand. The structural properties of demand are not yet to be sought in natural laws of cycles; they are anchored in utility theory. Little by little, Schultz abandoned references to a sui generis dynamic law of demand and constructed this law on the basis of a statistical static law of demand whose shifts from time to time would provide a dynamic law. Thus Schultz's (1928b, 23) criticism of the "neoclassical" theory of demand against the theory of the "mathematical school" was concentrated more on the impossibility of a ceteris paribus framework. By referring here and there to utility theory and to the influence of substitution on demand curves, Schultz (1931a) shows that integrating utility theory and statistical analysis of interdependencies is a possible direction of research at the beginning of the thirties, one he would always privilege against the use of budget data (Schultz 1933). Of the economists who may have inspired Schultz on the subject, Fanno seems to have been the most important. ${ }^{20}$ Among the first to suggest a possible path between choice theory and

18. A general presentation of the status of demand analysis within Moore's overall economic project is beyond the scope of this article. Moore would come back regularly in his other writings on the subject, with less optimism and less radically maybe, but still with great fidelity to his first ideas. Notably, he always considered multiple correlation as the best way to integrate a good number of related goods in the statistical laws of demand and in elasticity calculations (Moore 1917, 147-51). His approach is always the same and shows a good knowledge of Pareto and Walras and a constant search for improving techniques for measuring elasticity (Moore 1926; 1929, chap. 3).

19. It is mainly through the eyes of Schultz that I have been led to comment on Moore's work. Quite different assessments of Moore's work can be found in Stigler 1954, Christ 1985, and Mirowski 1990.

20. On the importance of related demands for statistical demand curves, Schultz (1938, 581) recognized Fanno's 1926 memoir as his main source of inspiration. 
statistical studies, Fanno (1933, 164) developed a correspondence between substitutability as it is represented with indifference curves and substitutability as it can be measured through the proportional variation of prices following any external shock on the demand for a good. He had already introduced this idea in his memoir (Fanno 1926) and again in 1929. Around 1930, Schultz $(1931 b, 83)$ was clearly looking in that direction, echoing Pareto's earlier statement:

The properties of the utility functions and indifference curves are very intimately related to certain characteristics of the laws of demand and supply. As an example, let us consider the demand and supply of an individual who has two or more commodities at his disposal. . . . When the consumptions of these commodities are not independent of one another, the quantity demanded may at first increase and then decrease with an increase in price, i.e., the demand curve may be positively inclined for part of its extent. . . . In [my] opinion, a study of these theoretical relationships will throw a flood of light on the problems connected with the derivation of demand curves from statistics.

Schultz developed this program in two steps between 1932 and 1935. However, complementarity was still to be defined within the framework of choice, and for that the main contribution came from Hicks and Allen.

\section{The Hicks-Allen Article}

The Hicks and Allen joint product-“A Reconsideration of the Theory of Value" - was published in 1934, in the February and May issues of Economica. It is of great importance to the extent that it opens up a new conception of the relationships between choice and the psychological foundations of choice. This is considered as true today as it was in 1934, and the Hicks-Allen article was immediately widely adopted-if not unanimously - as a solid foundation for demand theory. ${ }^{21}$

Among the subjects connected to choice and demand, the definition of complementarity is given much attention in the article. Hicks and Allen saw that all this was an inevitable necessity of the development of

21. In other respects, the Hicks and Allen article is outdated, especially for the debate on integrability and the role of the decreasing marginal rate of substitution for negative semidefiniteness of the Slutsky matrix (cf. Samuelson 1938a, 1938b, 1950). 
choice theory. ${ }^{22}$ The most significant transformation of the concept, and certainly what allows speaking of a revolution, is that complementarity and competitiveness will no longer appear as a relation between two goods dealt with apart from all other goods in the set of choice. From now on, economists will have to deal with two concepts, according to the kind of modeling they use. The first is "substitutability," represented by the coefficient of elasticity of substitution within the two-good case. The second is "complementarity and competitiveness" between goods, represented by the coefficient of "elasticity of complementarity" within the general case. This is certainly the most important achievement together with the now-familiar Hicksian distinction between a price effect and an income effect. In this article, Hicks and Allen provided a new definition of complements and substitutes that was fully articulated with the theory of demand. To that extent, it is legitimate to take this article as a watershed in the history of complementarity and of demand.

Below I present the Hicks and Allen article in three steps. First, I focus on elasticity of substitution. Second, I concentrate on the new definitions of substitutes and complementary goods. Third, I reflect on their enterprise from a methodological point of view.

\section{Demand Theory and the Elasticity of Substitution}

The whole analysis of choice and demand is based on the hypothesis of a decreasing marginal rate of substitution, which is presented as replacing the old hypothesis of decreasing marginal utility. Consider $R_{x}^{y}(x, y)$ the marginal rate of substitution of $x$ to $y$, that is, the quantity of $x$ that would exactly compensate the individual for the loss of one unit of $y$ (Hicks and Allen 1934, 55, 198). This marginal rate is given by the differential equation $d x+R_{x}^{y} d y=0$.

In the two-good case, the preferences of the individual can be entirely expressed (independently of market conditions) through three indexes of

22. Allen (1934c, 110) expressed what was at stake at the surface of things, that is, in the development of choice theory as a prerequisite for demand theory: "It is the existence of mutual relationships between goods, finding expression in the various forms assumed by indifference curves, that distinguishes the general theory of choice from the simpler and more artificial theory which serves in the case of one consumers' [sic] good only" (see also Allen 1934b, 486). Later in Value and Capital, Hicks was able to put things in a wider perspective: the Paretian theory of choice based on the analysis of complementary and competitive goods, he says, "started as an extension but ended as a revolution" ([1939] 1946, 13). 
elasticity: the elasticity of substitution $\sigma$ and two coefficients of income variation $\rho_{x}$ and $\rho_{y}{ }^{23}$ The measurement of substitutability is thus given by the elasticity of substitution between $X$ and $Y$ on a point (Hicks and Allen 1934, 59). ${ }^{24}$ (I follow the practice of Hicks and Allen in distinguishing between goods $X$ and $Y$ and the quantity consumed or chosen of those goods, $x$ and $y$.) The coefficients $\rho_{x}$ and $\rho_{y}$ express the relationships between two adjacent indifference curves along the $\mathrm{x}$-axis and the $y$-axis, respectively, and are called (rather misleadingly) the "coefficients of income variation." Those three coefficients are independent of any price or market data. From the hypothesis of a decreasing marginal rate of substitution, $\rho_{x}$ and $\rho_{y}$ cannot be negative simultaneously. ${ }^{25}$

Given prices $p_{x}$ and $p_{y}$ and a fixed income $\mu$, Hicks and Allen derive the decomposition of the effect of a price change of $p_{x}$ on the demands for $x$ and $y$. Having defined the budget coefficient $\kappa_{x}=x p_{x} / \mu$ and the income-elasticity of demand for $x, e_{\mu, x}=(\mu / x)(\partial x / \partial \mu)$, and having shown that $e_{\mu, x}=\sigma \rho_{x}$, the price-elasticities of demand $e_{p_{x}, x}$ and $e_{p_{x}, x}$ are decomposed into a sum of two effects, one involving $e_{\mu, x}$ (the income effect) and one involving $\sigma$ (the substitution effect).

$$
\left\{\begin{array}{l}
e_{p_{x, x}}=\kappa_{x} e_{\mu, x}+\left(1-\kappa_{x}\right) \sigma \\
e_{p_{x, y}}=\kappa_{x} e_{\mu, x}+\kappa_{x} \sigma
\end{array}\right.
$$

In this two-good case, the substitution effect provides an index of substitutability. Hicks and Allen note that the substitution term in $e_{p_{x}, y}$ "is always negative" (i.e., the compensated fall in the price of one good causes a substitution of this good for the other) and symmetrical in $x$ and $y$, thus being "a general measure of substitutability." ${ }^{26}$ Hence, as Allen underlined it, ${ }^{27}$ "Two goods must always be regarded as substitutes, or as 'competitive,' when they stand by themselves; complementarity is a char-

23. $\sigma=\left(d\left(\frac{x}{y}\right) /(x / y)\right) /\left(d R_{x}^{y} / R_{x}^{y}\right) ; \rho_{x}=\left(\partial R_{x}^{y} / \partial y\right) /\left(R_{x}^{y} / y\right)$ and $\rho_{y}=-\left(\partial R_{x}^{y} / \partial x\right) /\left(R_{x}^{y} / x\right) . \sigma$ takes all values between 0 and $\infty$.

24. In this article, it will be useful to disentangle the 1934 Hicks-Allen joint product. I refer to Allen's part as "Hicks and Allen" and to Hicks's part as "Hicks and Allen."

25. In the "normal" case, both coefficients are positive; in the "exceptional" case, one of them is negative.

26. Of course, the variation of demand relative to the price change of the other good can be either positive or negative, but it does not indicate complementarity or competitiveness.

27. Allen does not stand firmly on his terminology, for he refers to competitiveness either as a generic word in the two-good case or as a specific word (opposed to complementarity) in the general case. 
acteristic which does not appear until at least three goods are considered" (Hicks and Allen 1934, 202).

\section{The Concept of Complementarity}

Complementarity and competitiveness appear only in the general case, and it is thus possible to "look for observable evidence of the "competitive' or 'complementary' nature of the relations between the three goods" (Hicks and Allen 1934, 210). The change in the demand for $Y$ when the price of $X$ falls $\partial y\left(\mu, p_{x}, p_{y}, p_{z}\right) / \partial p_{x}$ splits into an income effect and a substitution effect (i.e., a substitution in favor of $X$ ). This substitution may take place at the expense of both $Y$ and $Z$ (as in the two-good case), and in this case $X$ and $Y$ are declared competitive (against $Z$ ), and $X$ and $Z$ are declared competitive (against $Y$ ). But substitution may also take place, differently, at the expense of $Z$ only while the quantity of $Y$ rises. In that case, $Y$ is complementary with $X$ against $Z$.

As noted by Hicks, this definition is not altogether free of market data and thus not a pure property of preferences, for it supposes implicitly that the reshuffling between $Y$ and $Z$ following the change in the price $p_{x}$ takes place without any change in the relative price $p_{y} / p_{z}$ : "Since there is implicit in our definition this assumption about price ratios, we have not succeeded in defining complementarity (as we ought to do) purely in terms of the individual's preference-scale; we are making a reference to the market which is better avoided" (Hicks and Allen 1934, 70).

Analytically, the differential equation of the indifference surface is $d x+$ $R_{x}^{y}(x, y, z) d y+R_{x}^{z}(x, y, z) d z=0$. The preference complex is now represented by nine indexes (in the integrable case). There are six distinct coefficients of the elasticity of substitution and one general coefficient $\sigma$ measuring mutual substitutability between goods. Three of the distinct coefficients represent the "ordinary" measure of elasticity of substitution (the elasticity of substitution between $i$ and $j$ being measured along the $i j$ plan, $k$ being fixed, ${ }_{i j} \sigma_{i j}$ ); the three others, "nonstandard" coefficients, measure the elasticity of substitution between $i$ and $j$ along another plan ( $i k$ or $j k$ ) (e.g., ${ }_{i k} \sigma_{j k}$ is the elasticity of substitution between $j$ and $k$ measured along the indifference direction $[i k], j$ being fixed) ${ }^{28}$ From those six coefficients and the general coefficient $\sigma$, Hicks and Allen have six new measures of elasticities of substitution and complementarity in the three-good case:

28. Under the integrability assumption privileged here, ${ }_{i k} \sigma_{j k}={ }_{j k} \sigma_{i k}$. 
1. $\sigma /_{y z} \sigma_{y z}, \sigma /_{x z} \sigma_{x z}, \sigma /_{x z} \sigma_{x z}$, being the three elasticities of substitution between one good and the pair of the two other goods (e.g., the first one is the elasticity of substitution between $X$ and the pair $Y Z$ ). They are always positive, as in the two-good case.

2. $\sigma_{x y}=\sigma /_{x z} \sigma_{y z}, \sigma_{x z}=\sigma /_{x y} \sigma_{z y}, \sigma_{y z}=\sigma /_{y x} \sigma_{z x}$ being the three elasticities of complementarity of a pair of goods against the third one (e.g., $\sigma_{x y}$ is the elasticity of complementarity of the pair $X Y$ against $Z$ ). If the elasticity of complementarity is positive, it denotes a complementary relation between two goods relative to the third one.

To those six coefficients, one must add

3. The three coefficients of "income-variation" $\rho_{x}, \rho_{y}, \rho_{z}$.

From this complete set of tools describing preferences in the threegood case, Hicks and Allen obtain the general expression of the effect of the variation of price on demand (Hicks and Allen 1934, 209) with still an income term (function of the income-variation coefficient) and a substitution term (a function of the elasticities of substitution and complementarity):

$$
\left\{\begin{array}{l}
e_{p_{x, x}}=\kappa_{x} e_{\mu, x}+\left(1-\kappa_{x}\right) \frac{\sigma}{y z} \sigma_{y z} \\
e_{p_{x, x}}=\kappa_{x} e_{\mu, y}+\kappa_{x} \sigma_{x y} \\
e_{p_{x, z}}=\kappa_{x} e_{\mu, z}+\kappa_{x} \sigma_{x z}
\end{array}\right.
$$

The second term in each equation of (2.2) indicates the substitution effect. Complementarity must be read on the second and third equations:

The effect of substitution following a fall in the price of $X$ is to increase or decrease the demand for $Y$ according as the elasticity of complementarity of $Y$ with $X$ against $Z$ is positive or negative. A negative elasticity of complementarity implies that $Y$ competes with $X$ against $Z$ and a positive elasticity that $Y$ complements $X$ against $Z$. The signs of the elasticities of complementarity determine the competitive and complementary nature of the relations between the three goods and their magnitudes indicate the extent of the relations. (211)

From those new definitions of complementarity and substitution in the general case, a few methodological and analytic remarks are in order. To implement a new definition is not without unexpected consequences, and it is important to catch all these consequences. 
Some Analytic and Methodological

Comments on Complementarity and

Substitutability in Hicks and Allen 1934

Hicks and Allen 1934 is filled with references to the methodological and analytic consequences of the new definitions of complementarity. While the authors insist that the new tools are quantitative ones, they also insist on unintended properties of the new definitions that may appear as more or less awkward. Hicks and Allen aim at breaking with the traditional theory of utility, hence the quantitative spirit that permeates the article. The consequences of the new theory of utility have to be worked out completely, they say, and new concepts must be developed: "It is hoped in this way to assist in the construction of a theory of value in which all concepts that pretend to quantitative exactitude, can be rigidly and exactly defined" (Hicks and Allen 1934, 55; emphasis added). ${ }^{29}$

Analytically, one can make some remarks about the new definitions. First, some traditional representations are dispelled. For instance, Hicks and Allen note that the cross-price effects on demand $\partial x\left(\mu, p_{x}, p_{y}, p_{z}\right) / \partial p_{y}$ and $\partial y\left(\mu, p_{x}, p_{y}, p_{z}\right) / \partial p_{x}$ are not symmetrical except when the income terms are of the same magnitude. Moreover, if income-effects terms are of opposite sign and relatively large compared with the elasticity of complementarity, then $\partial x / \partial p_{y}$ and $\partial y / \partial p_{x}$ will differ "not only in magnitude, but also in sign" (Hicks and Allen 1934, 214). The second remark deals with the number of complementary relationships within the economy. Hicks and Allen show that the three elasticities of substitution and complementarity between any two goods are linked by the following constraint:

$$
\left(1-\kappa_{x}\right) \sigma / \sigma_{y z}+\kappa_{y} \sigma_{x y}+\kappa_{z} \sigma_{x z}=0
$$

(and two other similar constraints relative to $x y$ and $x z$ ).

Consequently, $\sigma /{ }_{y z} \sigma_{y z}$ being necessarily positive, elasticities of complementarity $\sigma_{x y}$ and $\sigma_{x z}$ cannot be simultaneously positive, and hence "it is not possible for more than one pair of the three goods to be complementary" (213). ${ }^{30}$ Thus the new concept of complementarity, as it appears in a choice

29. For instance, the authors seem to insist on the fact that the principal advantage of the decreasing marginal rate of substitution over the decreasing marginal utility is that "it becomes significant and useful to ask: 'increasing how rapidly?'” (Hicks and Allen 1934, 58). This is precisely what the marginal elasticity of substitution is supposed to give: a measure of the curvature of the indifference loci.

30. See also Hicks and Allen 1934, 70; Hicks and Allen 1934, 211.

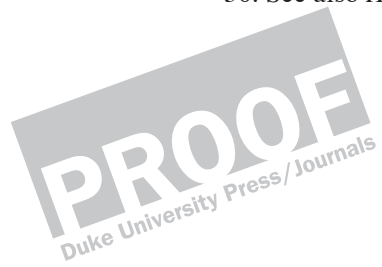


framework, implies some kind of asymmetry between complementarity and competitiveness from the outset.

The third remark deals with the generalization of the analysis to an $n$-good case. Nothing is said about the best way to account for complementarity and competitiveness in this general case $(n>3)$. As regards this, Hicks and Allen remain evasive as to what kind of generalization would be a good measure of complementarity and competitiveness. ${ }^{31}$

The fourth remark is about independence. There remains to be known what status will be given to independent goods (once the ALEP criterion is rejected for not being independent of monotone transformations of the utility function). Hicks and Allen reject the most immediate definition of independence as an intermediate situation between complementarity and competitiveness. Curiously, they appeal to a purely introspective idea of what independence should consist of: "For, if, as would happen at our watershed, the marginal rate of substitution between $Y$ and $Z$ is unaffected by compensating changes of $X$ and $Z$, this does not mean that the goods are in any useful sense 'independent' - there subsists a very complex relation between them" (Hicks and Allen 1934, 74).Hicks and Allen's development on independence is not very well articulated indeed. Hicks (Hicks and Allen 1934, 74-76) expands mainly on the idea that $X$ is independent of the pair $Y Z$ if the marginal rate of substitution between $Y$ and $Z$ is independent of the quantity of $X$. This definition does not prevent per se any type of relation between $X$ and $Y$ against $Z$ (either complementarity or competitiveness). Nevertheless, $X$ and $Y$ can be complementary only if $Y$ is an inferior good. Allen's mathematical treatment is centered on the hypothesis of mutual independence between $X, Y$, and $Z$ (Hicks and Allen 1934, 214-18). As shown from all those analytic remarks on complementarity, we can draw a first conclusion. The first effect of this reconstruction of demand theory is that the whole conception of complementarity is metamorphosed. Complementarity and substitutability appear now as derivative concepts and necessarily lose the autonomy characteristic of the ALEP definition. At the same time, complementarity and competitive-

31. Hicks will tackle this question in Value and Capital through the use of a "composite commodity" (see the following section). It is nevertheless interesting to wonder about the minimum number of competitiveness relations in an $n$-good case. In this case, there are $n$ constraints similar to (2.3) and thus at least $n$ pairs of competitive goods in the whole system. Compared with the total number of complementarity or competitiveness relations $n(n-1)(n-2) / 2$, the minimum number of competitiveness relations is shrinking as the number of goods is increased. 
ness are at least given a theoretical content within the theory of choice and demand. ${ }^{32}$ Consequently, competitiveness and complementarity are now coextensive with the new theory of demand, ${ }^{33}$ and the metamorphosis of the concept would not be challenged for long. ${ }^{34}$

Another question is to know how Hicks and Allen were led to this reconstruction of demand theory. It is beyond the scope of this article to enter precisely into a genetic history of the Hicks-Allen article. It is nevertheless remarkable that, according to Allen $(1935,158)$, the main interest of the new definition is that it "applies at once in the explanation of the inter-relations of individual demands under market conditions," a subject of interest for econometricians, as we have seen. To put it in a few words, Hicks and Allen 1934 is the product of two converging topics. First, there is Hicks's decomposition between income and price effects linking elasticity of substitution and elasticity of demand. ${ }^{35}$ Second, there

32. For all that, the new definitions are not completely deprived of introspective qualitiesthat complementarity between two goods depends on which third good is associated to the choice and, more generally, on the context of choice.

33. Hicks and Allen are quite explicit about that when they deal with the two-good case: "It is perfectly consistent with the theory we have so far elaborated, to suppose that all goods are more or less related in consumption; yet we have made no use of the conception of complementarity and competitive goods. We have not used it, because we had no need to use it; we had not yet come to the problem where it is relevant" (Hicks and Allen 1934, 69).

34. Later, as he would comment on the Hicks-Allen definition, Allen insisted on the fact that the new definition was radically different from the ALEP definition, that it was something else and that economists were progressively discovering how different it was: "It is becoming increasingly evident, as its implications are worked out and its range extended, that this [Hicks-Allen] definition of complementarity provides a more constructive tool than the notoriously barren one based on the sign of the cross second-order derivative of the utility function. It must not be supposed, further, that the new definition and the old coincide when utility is taken as measurable - the new definition is not only wider but radically different from the old. Even when the utility function is determinate, the sign of the cross derivative cannot be expected to give results in this field of complementarity. Surely we have here something more than an 'axiomatic experiment'" (Allen 1935, 158 n). For all that, one must keep in mind that (1) some authors have challenged the new definition on the occasion of a debate on "intrinsic complementarity" inaugurated by Oskar Lange (1940); and (2) Allen's statement does not preclude searching for empirical implications of ALEP complementarity (Chipman 1977, Weber 2000).

35. The Hicksian decomposition is heuristically different from Slutsky's "residual variations," and it cannot be justified on empiricist grounds. It is rather a purely instrumental device based on the unobservable concept of indifference curves and hence possessing other heuristic advantages (Chipman and Lenfant 2002). The textual evidence in Hicks and Allen 1934 leads the reader back to a debate following Hicks's Theory of Wages ([1932] 1957) and Robinson's The Theory of Imperfect Competition (1933) and their independent introduction of the concept of elasticity of substitution. The debate took place mainly in the Review of Economic Studies and is referred to incidentally in Hicks and Allen 1934, 59 n. Hicks would 
is a desire to expand demand analysis to interrelations of demand in a general framework $(n \geq 3)$ and thus to provide a new definition of complementarity, as Allen had been convinced of through his earlier articles. ${ }^{36}$ Behind this was also a growing interest for econometrics and for the questions raised by econometrists. As Hicks $(1981,3)$ recounted later, the 1934 article "also reckoned, quite explicitly, among the things that gave rise to it, Joan Robinson's definition of elasticity of substitution (e.s.) and a question about complementary goods that had been raised by Henry Schultz (of Chicago). It is thus not surprising that it made a noise in the world of economists." ${ }^{37}$ So we are led back to Schultz and to the econometrics of complementarity.

\section{Constructing the Hicks-Slutsky Theory of Demand}

As was shown in section 1, around 1930, Schultz wished to tie the econometrics of demand with the theory of demand based on rational choice. Soon after, he implemented the Hicks-Allen theory of value into the econometrics of demand. There are two stages to this story. To begin with,

always insist on the influence of Robbins's seminar on the 1934 article: it was also "the product of discussions, in which several others took part, in the Robbins seminar at LES" (Hicks 1981, 3). Also, Hicks would give some insights of his own evolution during those years on many occasions. Hicks (1973, 3 n) sketched his own way from Theory of Wages to Hicks and Allen 1934 very succinctly: "Theory of Wages elasticity of substitution; Joan Robinson's elasticity of substitution (Imperfect Competition) 1933; proof of equivalence in two-factor case; Lerner's proof that the Robinson elasticity is a property of an isoquante; my own realization that the same geometrical property would hold for an indifference curve. Those are the steps that led to the Hicks-Allen article." See also Hicks 1981, 3-5.

36. Allen was trained as a statistician at the LSE, and he maintained an interest in choice and utility theory throughout his career, from the time of his first published article, "The Foundations of a Mathematical Theory of Exchange" (1932). He then wrote some other articles on complementarity before cooperating with Hicks (Allen 1934a, 1934b, 1934c). Taken together, these articles provide a thorough study of ALEP complementarity in relation to indifference curves and utility functions. Allen was certainly the first economist to grasp the central importance of complementarity as a consequence of Paretian choice theory: "It is the existence of mutual relationships between goods, finding expression in the various forms assumed by indifference curves, that distinguishes the general theory of choice from the simpler and more artificial theory which serves in the case of one consumers' good only" (1934c, 110). Hicks had been acquainted with the subject of complementarity and choice theory by reading Allen's articles on the subject. Hicks presented the final product by saying that "the present paper is the result, first, of my own reflections about Mr. Allen's work, and secondly, of our collaboration in working out the details of a theory which shall be free of the inconsistencies detected in Pareto" (Hicks and Allen 1934, 55). Thus it is clear that Allen's articles had circulated among economists at the LSE.

37. Allen (1934b) also mentioned Schultz 1933. 
in 1933 Schultz "tests" symmetry conditions on demand systems obtained by Hotelling (1932). Subsequently, facing bad statistical results, Schultz hints at the Hicks and Allen article and at the Slutsky article to test new kinds of theoretical relations: the Slutsky symmetry conditions. Between 1933 and 1938 Schultz develops a sophisticated analysis of complementarity and a justification for the simpler cross-price effect definition based on Hotelling's previous analysis. This led to Hicks's reformulating the theory of demand in Value and Capital, which resulted eventually in the classical theory of the consumer.

\section{The Schultz-Hotelling Tests on Demand Functions}

In 1932 Hotelling and Schultz were searching for structural relations between demand functions, and they found similar theoretical constraints that Schultz and his team at Chicago would endeavor to test. The SchultzHotelling cooperation on demand theory dates back to Hotelling's article "Edgeworth's Taxation Paradox and the Nature of Demand and Supply Functions." In this 1932 article, Hotelling proposed two conditions under which an apparently counterintuitive relationship might appear. Edgeworth ([1897] 1925) had shown that the taxation of a monopolized product might imply a lowering of its price. Hotelling shows that this result is not conditioned by the market structure (it might take place also under free competition). Hotelling's model led to symmetry conditions on cross-price elasticities of demand for two goods. His article is interesting because it is based on the same observation as Schultz's, that is, that demand studies are characterized by a gap between deductive statements on demand and purely inductive statistical relations. Thus Edgeworth's paradox stimulated "a critical examination" of the idea that "demand functions for several commodities need satisfy no conditions except the decrease of demand for each commodity when its price increases" (Hotelling 1932, 582). To sum up, Hotelling's main idea is that the study of a multigood system might produce additional structure on demand relationships and that most of the poorly motivated properties of demand in the economic literature are due precisely to the fact that "the correlation of demand for different commodities is neglected" (583).

Through a multigood analysis, Hotelling provides structural constraints—the famous "Hotelling's integrability conditions" 38 - on demand

38. Those integrability conditions are different from the Slutsky integrability conditions rejected by Allen and Samuelson (see Chipman and Lenfant 2002). 
systems that can be deduced from the maximizing behavior of economic agents. ${ }^{39}$

$$
\partial x_{i} / \partial p_{j}=\partial x_{j} / \partial p_{i}
$$

Thus the cross-partial derivatives of demand functions are equal.

What is of interest to us is that many related goods are considered at once and lead to structural relations on demand functions that can be tested statistically. As he later commented: "Theoretical conditions exist with which empirical results may be compared" (Hotelling 1933, 409).

Schultz's $(1933,506)$ own model was presented soon after in "Interrelations of Demand," following Hotelling's idea that "economic theory lays down certain conditions which the demand functions for any two related goods must fulfill. These are the conditions of consistency (integrability conditions)." ${ }^{40}$ The main result of Schultz's article was that statistical tests led to the conclusion that the "integrability conditions" were not satisfied exactly. ${ }^{41}$ That is, the results were sufficiently bad to warrant searching for more general conditions.

Schultz's consistency conditions were the same as Hotelling's but were deduced from a Paretian model based on maximizing utility under fixed income and with the hypothesis of a constant marginal utility of money income (thus allowing symmetric income effects and the symmetry of cross-partials of demand functions) (478, equations 19 and 20). The econometric system to be tested (supposing linear demand curves) is thus:

39. In fact, Hotelling's constraints derive from two different models. The first one is a nonstandard model with entrepreneurial demand functions; the second one is based on a fixedincome hypothesis. The detail of mathematical notations is to be found in Hotelling 1935, 68 . Hotelling's model differs sensibly from the Paretian model to the extent that there is neither a fixed income nor an income determined by the price of the initial endowments and that the functions describe what is now called "entrepreneurial" demand functions. But the results are the same as under the hypothesis of fixed income and constant marginal utility of money. In Hotelling's view $(1932,592)$, his model was depicting something more general than the Paretian model of consumer behavior, and it is adapted to a great variety of consumption circumstances. Hotelling does not provide any justification for this. On this model and its interpretation, see Hands and Mirowski 1998 and Chipman and Lenfant 2002.

40. That Hotelling and Schultz made simultaneous discoveries is not surprising. Indeed, Schultz and Hotelling's research went hand in hand for two years. We know from Hotelling 1939, 100, that Schultz had been a referee for the first draft of the 1932 article and that Schultz had informed Hotelling that he had found similar conditions under the constant marginal utility hypothesis (Hands and Mirowski 1998). In fact, Schultz's (1933, 481 n. 16) findings were stimulated by his reading of Hotelling's draft. This "collaboration" led to a sustained correspondence between Hotelling and Schultz that has been commented on by Hands and Mirowski (1998).

41. In his 1932 article, Hotelling already mentioned (in the note on page 594) that Schultz and his staff had not found promising results. 


$$
\left\{\begin{array}{l}
x_{i}=h_{i}+r_{i, i} p_{i}+r_{i, j} p_{j} \\
x_{j}=h_{j}+r_{j, i} p_{i}+r_{j, j} p_{j}
\end{array}\right.
$$

In this model, $r_{i, j}$ and $r_{j, i}$ will be negative in the case of complementary goods and positive in the case of competing goods. That Schultz preferred his own formulation of the model is due mainly to its heuristic properties. Interestingly, what Schultz meant in this case was that his model and the symmetry properties could be easily related to intuitive properties of the ALEP definition of complementarity. Thus, in 1933, Schultz was still attached to an introspective conception of complementarity based on utility:

I prefer, however, to adopt as my point of departure the fundamental classical definitions of related and independent commodities in terms of the utility functions, for these functions seem to me to lead more directly to the characteristics of the related demand equations with which we shall be primarily concerned in this paper, and to have other heuristic properties as well. (481 n. 16) $)^{42}$

Schultz makes a statistical test of those consistency conditions for four agricultural products: barley, corn, hay, and oats, with the idea to determine which pairs are completing and which ones are competing. One pair of goods will show a significant contradictory result, and symmetry conditionsthus are not satisfied. Considering that the symmetry conditions should at least be approximately satisfied, the subsisting contradiction is commented on as follows, using the ALEP heuristics: "It is as though the relation between the two commodities were such that the utility of hay to farmers increases as the quantity of oats is increased, while the utility of oats decreases as the quantity of hay is increased! But such an explanation cannot be entertained" (Schultz 1933, 501). ${ }^{43}$ At this stage, one can conclude that the first encounter of the Paretian theory of demand and statistical studies of demand is met with mixed success. The

42. In the same article, Schultz $(1933,481)$ also vindicates not following Fanno's heuristics, because it does not lead to testable relations (see also Court 1941, 139). On the same footing, Hotelling (1935), coming back to the subject, does not adhere to Schultz's procedure and heuristics and shows some reluctance to adopt the fixed-income hypothesis. This is due to an attachment both for the physical analogy he had developed earlier and for a general equilibrium model without the hypothesis of the constant marginal utility of money (Hotelling $1935,74) . H e$ is also more generous with Schultz's results $(67 \mathrm{n})$. On the justification of the fixed-income hypothesis, see Schultz 1935, 436.

43. Among the main reasons that may explain those disappointing results are that some other related goods may have been forgotten (Schultz 1933, 480n1, 510). 
Hicks and Allen article, together with the rediscovery of the Slutsky article, are coming at the right time. It is to be expected that they will also affect the methodological justification of the model and the interpretation of the results.

\section{The Schultz-Slutsky Model}

In 1934 Schultz benefited not only from Hicks and Allen's article but also from the discovery of Slutsky's article (Chipman and Lenfant 2002). Both contributions were received at the precise moment when Schultz was looking for new theoretical relationships on demand systems that might be tested. In "Interrelations of Demand, Price, and Income" (1935) - and again in his 1938 treatise-Schultz would devote most of his energy to developing the theory of related goods and its applications on the basis of Slutsky-Hicks-Allen demand analysis. To that extent, Schultz shares with Hicks and Allen the paternity of a modern theory of complementarity.

Two aspects of Schultz's work demand attention. First, he adapted Hicks and Allen's work in order to make it operational for statistical computation, and in this respect he preferred Slutsky's decomposition between price effects ("residual variability") and income effects. Second, Schultz abandoned the psychological introspective framework associated with the ALEP definition, adopting instead a new methodological credo for economics - the so-called operationalist methodology (after Bridgman 1927) to which he meant to associate the Hicks-Allen definition. To that extent, his interpretation of Pareto's recommendations appears, at first sight, more radical than Slutsky's and even Hicks and Allen's. For all that, it does not imply that Schultz is abiding strictly by an operationalist methodology in his reasoning. Neither does it mean that the reference to an operational procedure is a self-fulfilling argument to build an econometric analysis of demand. Indeed, Schultz (1935, 474-75 n. 47) eventually shows a preference for Hotelling's symmetry conditions. Thus Schultz's arguments and methodological references are worth discussing further.

It is beyond the scope of this article to appraise Schultz's implementation of the operationalist methodology into economics. ${ }^{44}$ Nevertheless, Schultz's reflection on demand theory and complementarity is best under-

44. On operationalism in general and its application in economics, see Caldwell 1982 , chaps. 2, 9; Chipman and Lenfant 2002; Mirowski 1998; Mongin 1988, 2000. 
stood if one makes clear how he articulated different levels of argumentation: first, the reference to operationalism and to "operational procedures" in economics, then the practical use of this operational procedure for selecting one definition of complementarity, and finally the effective choice of one model of demand. Let us take each of those levels one at a time.

Schultz's references to operationalism are not mere references to the methodology of the natural sciences. Although Schultz is certainly searching for scientific criteria that may put economics on the same footing with physics, his frequent references to Bridgman 1927 testify that he considered Bridgman's recommendations seriously for economics. This does not mean that Schultz is a strict operationalist. In his comments on Bridgman, Schultz $(1938,11)$ stresses the fact that economics will gain in making "a distinction between concepts which are defined in terms of operations and those which are defined in terms of properties of things." The focus on operational procedures is presented as the main criteria for selecting one concept of complementarity over another. In Schultz's own words: "The restatement and extension of the earliest concept of demand into forms which have meaning in terms of operations, which has been attempted in the foregoing pages, is the first step in the direction of the derivation of concrete statistical laws of demand" (12).

As an illustration of this method, Schultz's comments on the HicksSlutsky definition make it explicit that according to him, operational concepts in economics should be based above all on market data rather than on experimental data. In this respect, the ALEP definition cannot be recommended because it is not reducible to the observation of market data:

According to [the ALEP definition], if we wish to know whether two commodities are completing, independent, or competing to an individual, we must ask him (and he must be able to tell us) whether, as we increase the quantity of one of the goods, the final utility of the other increases, remains constant, or decreases. The operation calls for an introspective comparison of final degrees of utility, on his part. The size of his income and the number of commodities in the economy do not affect his ability to make the comparison in question. According to [the SHAS definition], if we wish to know whether the individual considers two commodities as completing, independent, or competing, we must note his income, and observe whether a fall in the price of one of the goods, accompanied by a compensating variation in his income, will cause him to increase, maintain constant, or decrease his purchase of the other... The point is ... that the answers 
called for by [the SHAS definition] do not require a comparison of final utilities and may be obtained by observing the individual's market behavior; whereas the answers called for by [the ALEP definition] cannot be so obtained." (Schultz 1935, 462-63)

As a third step in this analysis of Schultz's methodology for statistical demand studies, the selection of a statistical model of demand is based on instrumental considerations. In this respect, Schultz was led to prefer a model leading to the Hotelling symmetry conditions rather than the more general one based on Slutsky symmetry conditions. First, Schultz (1935, 457) noted that Hotelling's symmetry conditions are true only under special circumstances, and that "although [they] . . . are approximately satisfied by several concrete, statistical demand analyses, they rest on weak foundations." In contrast, the more general Slutsky symmetry conditions lead to a new definition of complementarity. Two goods $x$ and $y$ are complementary (or completing) if (458)

$$
\frac{\partial x}{\partial p_{y}}+y \frac{\partial x}{\partial R}=\frac{\partial y}{\partial p_{x}}+y \frac{\partial y}{\partial R}<0
$$

The system of linear demand functions to be tested is

$$
\left\{\begin{array}{l}
x=c_{1}+c_{1,1} p_{x}+c_{1,2} p_{y}+c_{1, R} R \\
y=c_{2}+c_{2,1} p_{x}+c_{2,2} p_{y}+c_{2, R} R
\end{array}\right.
$$

Then, $x$ and $y$ are complementary whenever (460)

$$
c_{1,2}+y c_{1, R}=c_{2,1}+x c_{2, R}<0 .
$$

Schultz provides statistical tests on those relationships for beef, pork, and mutton, using multiple regression. The quantity of each good is expressed as a function of the price of the three goods and of income. Schultz also tests pairs of goods (beef-pork, beef-mutton, pork-mutton). Results appear to be even worse than in the 1933 article. The only conclusion drawn from those tests is that the price of each good is the most influential variable on its demand and that it is an obstacle to a careful analysis of complementarity (Schultz 1935, 472). Drawing the lessons from those articles, Schultz seemingly came to see that many difficulties were obviating the test of symmetry conditions. Actually, Schultz's argument in favor of the Hotelling symmetry conditions over the Slutsky conditions is based on acknowledging the failure of the Slutsky symmetry conditions to 
improve the quality of statistical estimations. Considering that nothing had been gained by using Slutsky symmetry conditions, and that "Hotelling conditions and the corresponding Slutsky conditions are of approximately the same order of magnitude" (479) because of the smallness of aggregate income effects, ${ }^{45}$ Schultz eventually advocated that the use of Hotelling's conditions might be enough to indicate "the type of relation existing between the two commodities" (479n51). So Schultz tended to regard income effects as relatively marginal compared with direct price effects, so that Hotelling's conditions might be verified as well as Slutsky's conditions at the market level without being open to any objection regarding the aggregation procedure (475). At this last stage in the construction of a statistical model of demand, the reference to an operational procedure is of no use, and Schultz is just selecting the best model.

In a few words, one must distinguish between two types of arguments in Schultz's work on complementarity. On the one hand, the so-called operationalist methodology is referred to as a justification for abandoning the ALEP definition, whereas, on the other, the final choice between different statistical models is justified on more instrumental grounds. ${ }^{46}$ In the final analysis, Schultz's attitude toward disappointing results on the tests of symmetry conditions is oscillating between either the need to improve on statistical techniques or a disenchanted benign-neglect in favor of a simpler model of related demands.

45. The conclusions are the same whatever the functional representation chosen (Schultz 1935, fig. 5, 478).

46. Friedman (1934), as one of Schultz's assistants at Chicago, provided a new definition of complementarity that enlarged the Johnson and Allen definitions. It was inserted partly into Schultz 1938. Friedman participated actively in preparing Schultz's 1935 article and in the corresponding eighteenth chapter of Schultz 1938 (cf. Chipman and Lenfant 2002). In The Theory and Measurement of Demand, Schultz $(1938$, chaps. 18, 19) would carefully compare the relative merits of each definition. Comparing the Johnson-Allen-Friedman preference-based definitions of complementarity with the Slutsky-Hicks-Allen-Schultz (SHAS) definition, he also reassessed the advantages of the "special" theory of related demands (based on the constant marginal utility of money hypothesis) over the more complicated "general" theory of related demands. The main reason for not retaining the Johnson-Allen-Friedman definitions is that the conditions for statistical applications are too remote because the relation between goods is defined over the whole indifference map and thus necessitates having an estimate of demands on the whole choice set (Schultz 1938, 612). Another weakness for statistical economics is that the relation between goods is supposed to be the same whatever the combination of goods (614; see also page 619 for a comment on Friedman's definition). On the contrary, the SHAS definition, as it is constructed on the basis of Slutsky's compensating variations, depends on market conditions (income and relative prices) and can be obtained from statistical information (subject to restrictions on aggregation). Thus choice theory provides "quantitatively definite relations" from which it is possible "to test the agreement between theory and facts" (Schultz 1938, 646). 
It is probable that the income effect is also small for most articles of wide consumption on which only a small proportion of the income is spent. We may, therefore, expect the simpler Hotelling conditions to be satisfied by a large number of demand phenomena. But this supposition needs to be fortified by more extensive statistical investigations. (Schultz 1938, 646)

Despite the mitigated success of Schultz's endeavor at this stage, it still had an effect on the theory of choice. Schultz's influence will be perceptible through the synthesis of the theory of demand by Hicks, once he came back to the subject after his collaboration with Allen.

Constructing the Hicks-Slutsky Theory

of Demand and Complementarity and

Reconsidering the Marshallian Orthodoxy

What still needs to be recounted is to what extent and how the SchultzSlutsky and Hicks-Allen reconstructions of demand theory were eventually synthesized as the Hicks-Slutsky theory of demand in Hicks's Value and Capital and subsequently in most standard textbooks.

We have seen that Schultz preferred to construct his analysis of demand on Slutsky's equations because they were more adapted to statistical handling. He had first expressed his disappointment about the bad results obtained from testing the Hotelling and Slutsky symmetry conditions, imputing the fault not to the model but to the weakness of statistical tools (Schultz 1935, 472). It is nevertheless quite striking that Schultz came to consider that income effects were so small as to block any effort to test Slutsky symmetry conditions.

This development of the econometrics of demand was not without influence on Hicks, and it is certainly the major incentive toward the synthesis of demand theory that was exposed in Value and Capital. Already in his 1937 booklet, Hicks had exposed demand theory on the basis of Slutsky's equation; later in Value and Capital, he would mix both presentations ${ }^{47}$ Hicks also enlarged the definition in the $n$-good case through introducing a composite commodity ("money") whose relative prices are constants, so that the presentation fits with the usual

47. The literal and geometrical representation in the full text is in the Hicksian manner, whereas the analytic presentation in the appendix follows Slutsky's compensation (Hicks 1939, 309). Later Jacob Mosak (1942) showed that the Slutsky and Hicks decompositions are equivalent for infinitesimal price variations. 
presentation in a three-good framework: two goods and "money." ${ }^{48}$ Hence the definition of complementarity is now expressed in this way:49

Suppose that $Y$ (one of the other commodities) is complementary with $X$-according to our definition of complementarity. Then we know that if the amount of $Y$ is held constant, a substitution in favour of $X$ and against money (now other goods than $X$ or $Y$ ) will raise the marginal rate of substitution of $Y$ for money. Now the price of $Y$ in terms of money is given and constant; so a rise in the marginal rate of substitution of $Y$ for money must encourage a substitution of $Y$ for money, if the marginal rate of substitution of $Y$ for money is to be kept equal to the price of $Y$. Therefore, if $Y$ is complementary with $X$, a substitution of $Y$ for money tends to be accompanied by a parallel substitution of $Y$ for money. The substitution in favour of $X$ stimulates a similar substitution in favour of $Y$. On the other hand, if, on our definition, $Y$ is a substitute for $X$, a substitution of $X$ for money ( $Y$ constant) encourages a substitution in favour of money and against $Y$. The substitution in favour of $X$ tends to be accompanied by a substitution against $Y$. It is our definition of complementarity which draws the exact line between these two situations. (Hicks 1939, 46)

As Samuelson $(1950,379)$ later remarked, Hicks's introduction of money was definitely putting the Hicks and Allen theory at the same level of generality with the Schultz-Slutsky presentation, thus inaugurating the nowstandard Hicks-Slutsky theory of demand:

In 1939, Hicks seems to have abandoned this definition in favour of the Slutsky-Schultz definitions; for $n=3$, the results of either definition are qualitatively the same. For $n>3$, this is not true. If we define all but the two goods in question to be a Hicksian composite commodity, then the Slutsky-Hicks definition can be cast in Hicks-Allen terminology.

Another probable instance of Schultz's influence on Hicks, although it must be advanced cautiously, is that the income effects are so negligible that it is best to work with Hotelling's symmetry conditions. Although Hicks advocated a general theory of value, he did not intend to repudiate Marshallian simplifications at all. Regarding the Marshallian theory of demand, Hicks went on to confess in Value and Capital that "further

48. "So long as the prices of other consumption goods are assumed to be given, they can be lumped together into one commodity 'money' or 'purchasing power in general' " (Hicks 1939, 33).

49. For a geometrical representation, see Hayek 1943 and Samuelson 1974. 
investigation has only increased my admiration for Marshall's theory; I hope the reader will find the same" (11). Regarding the constant marginal utility of money assumption, Hicks wants to show, through the general formulation of the law of demand, that Marshall had just made "an ingenious simplification" and had "quite good reasons" for doing so (27). And now that economists do have a general theory of demand, they can indulge in Marshallian simplification, in full knowledge of what they are neglecting (32-33). In some respects, Hicks's justification for preserving the law of demand is based on the idea that in most economic situations, income effects are small enough compared with substitution effects, which is tantamount to Schultz's statistical estimations. In other respects, Hicks is more cautious than Schultz and would not regard those results as a litmus test in favor of the law of demand. For instance, Hicks's statement about the law of demand is based also on considerations on general equilibrium, aggregation on goods and individuals, whereas Schultz does not consider carefully the many intrinsic limits of his model (regarding exogenous income or linear demand functions).

Theoretical considerations apart, it is quite probable that Hicks's earlier intuitions on income effects must have been reinforced by Schultz's comments. As Hicks later confessed on many occasions, the reconstruction of demand theory was clearly driven by the development of econometrics. Hicks (1956b, vi, vii) claimed, in the introduction to the French translation of Value and Capital, that "economic theory must be the servant to applied economics" and also that "the first part [of Value and Capital], which deals with demand theory, was inspired by the work of old econometricians, especially the articles from Henry Schultz." And in A Revision of Demand Theory, he again acknowledged that in Value and Capital "at crucial points the argument was put in a form which was influenced by what the econometrists had been doing," and he also asserted that the end of the story inaugurated by Pareto and followed by Slutsky, Johnson, Hicks, and others was to make "the Pareto theory more usable and ... [to weave] the Marshallian and Paretian threads together" (Hicks 1956a, 3).$^{50}$ The econometric concern, if not the sole concern, was quite clear, as Hicks (1981, xii) puts it:

It was not explained, in the Hicks-Allen paper, what prompted us to make our enquiry. It began in fact from econometrics. It was the work of Henry Schultz, on statistical demand study, which set us off. What

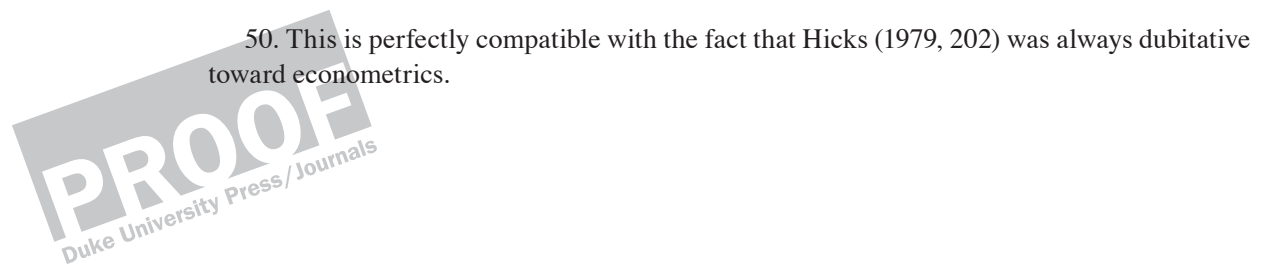


we were doing was to reformulate demand theory so as to put it into a form which would be more usable by econometrists.

Thus it is not to be doubted that there were cross-influences between Schultz on the one side and Hicks on the other. Was this of any influence on econometrics and economic theory at the time? At least two strands of work can be seen as a good testimony for the solid implantation of the Hicks-Slutsky synthesis in price theory. First, Hicks and Allen's article influenced econometrists and their offspring in the late 1930s, especially, although not only, at the Cowles Commission (Hands and Mirowski 1998, 374). Gerhard Tintner's (1938) theory of dynamical demand curves is an extension of Hicks and Allen; Jacob Marschak (1943) refers to Hicks and Allen to estimate individual demand functions; Jacob Mosak (1938) provides an extension to the demand of productive services; and E. E. Lewis (not at Cowles), through a series of articles on intercommodity relationships $(1937,1938 \mathrm{a}, 1938 \mathrm{~b})$, is still another example of work done under the guidance of Hicks, Allen, and Schultz. Second, the whole development of general equilibrium, at least until the 1950s, is centered on discussing income and price effects, aggregation, and above all stability, always with Value and Capital as a reference. But this is another story. ${ }^{51}$

\section{Conclusion}

A first conclusion deals with the idea of a stabilization of demand theory around the Hicks-Slutsky synthesis. My claim in this article is that the development of a modern theory of demand in the 1930s was not exclusively motivated by the use of an index utility function but that it was motivated also by the need to define the concept of complementarity and to give to it a definition adapted to the construction of a theory of choice. To that extent, the most important result of the Hicks-Allen definition is not the Hicksian decomposition itself; rather, it is the use of this decomposition to study both the law of demand and the law of related demands. This result has been made possible only through a complete transformation of the concept: its meaning and its analytic definition have been changed drastically. Notably, after Hicks and Allen 1934 it is no longer

51. My narrative is stopping at a time when divergent approaches would challenge the Hicks-Slutsky presentation of demand. But challengers do not hesitate to take the HicksSlutsky theory as their main target (Knight 1944; Friedman 1949; Samuelson 1938a, 1938b) (although for different reasons and with divergent aims). 
possible to interpret complementarity as a binary relationship between two goods (and an individual) taken apart from the context of choice. On the contrary, the context of choice is a constituting part of the definition.

A second conclusion is about the progressive transformation of the concept. At both extremes-the introspective properties and the operational properties-one may feel that complementarity was quite evidently and naturally transformed by the ordinalist principles. Things are not so simple. From all those debates, it is clear that the properties of the concept are as important at the end of the story as at the beginning. ${ }^{52}$ The road taken to develop a new concept is not straightforward or reducible to a technical challenge. It is rather the product of many constraints: on testability, on the operational aspects of economic concepts, on intuitive properties of complementarity, on homogeneity of definitions. For instance, is it necessary that one should tell if two goods are completing or competing in any circumstances or just in given economic circumstances? Shall we impose a priori that completing goods are as likely to occur as competing ones? What should be the heuristic behind the concept? Shall we privilege homogeneous definitions of all types of relations, or shall we accept, for instance, to define independence in a peculiar way or to refer to different types of complementarities or competitiveness? Shall we privilege concepts that are appropriate for statistical handling, or shall we rather search for definitions that fit some intuitive (or subjective, or introspective) representations? All those questions have been addressed here and there, and the answers have never been dictated by one single a priori principle to demarcate ordinalism and cardinalism. Quite the contrary, answers depended on many different constraints and ideas about what should be a good concept of complementarity.

\section{References}

Allen, Roy. 1932. The Foundations of a Mathematical Theory of Exchange. Economica 12:197-226.

1934a. A Comparison between Different Definitions of Complementary and Competitive Goods. Econometrica 2:168-75.

— 1934b. Nachfragefunktion für Güter mit korrelierten Nutzen. Zeitschrift für Nationalökonomie (January): 486-506.

- 1934c. The Nature of Indifference Curves. Review of Economic Studies 1.2:110-21.

52. Notably, this was the case in a series of articles on "intrinsic complementarity" (cf. Lange 1940). 
1935. A Note on the Determinateness of the Utility Function. Review of Economic Studies 2:155-58.

Auspitz, Rudolf, and Richard Lieben. [1889] 1914. Recherches sur la théorie du prix. Paris: Giard et Brière.

Baumol, W. J., and S. N. Goldfeld. 1968. Precursors in Mathematical Economics: An Anthology. Series of reprints of scarce works on political economy, no. 19. London: London School of Economics and Political Science.

Benini, Rudolfo. 1907. Sull'uso delle formole empiriche nell'economia applicata. Giornale degli economisti, 2nd ser., 25 (November): 1053-63.

Bridgman, Percy. 1927. The Logic of Modern Physics. New York: Macmillan.

Caldwell, Bruce. 1982. Beyond Positivism: Economic Methodology in the Twentieth Century. London: Allen \& Unwin.

Chipman, John. 1976. The Paretian Heritage. Revue Européenne de Sciences Sociales et Cahiers Vilfredo Pareto 14.37:65-173.

— 1977. An Empirical Implication of Auspitz-Lieben-Fisher-Pareto Complementarity. Journal of Economic Theory 14:228-31.

Chipman, John, and Jean-Sébastien Lenfant. 2002. Slutsky's 1915 Article: How It Came to Be Found and Interpreted. HOPE 34.3:553-97.

Christ, Carl. 1985. Early Progress in Estimating Quantitative Economic Relationships in America. American Economic Review 75:39-52.

Court, Louis. 1941. Invariable Classical Stability of Entrepreneurial Demand and Supply Functions. Quarterly Journal of Economics 56:134-45.

Dooley, Peter C. 1983. Slutsky's Equation Is Pareto's Solution. HOPE 15.4:513-17.

Eatwell, John, Murray Milgate, and Peter Newman, eds. 1987. The New Palgrave: A Dictionary of Economics. 4 vols. London: Macmillan.

Edgeworth, Francis Ysidro. [1897] 1925. The Pure Theory of Monopoly. In vol. 1 of Papers Relating to Political Economy. London: Macmillan.

Ezekiel, Mordecai. 1927. A Statistical Examination of Factors Related to Lamb Prices. Journal of Political Economy 35:233-60.

- 1933. Some Considerations on the Analysis of the Prices of Competing or Substitute Commodities. Econometrica 1:172-80.

Fanno, Marco. 1926. Contributo alla teoria dei beni succedanei. Annali di economia, special issue.

— 1929. Die Elastizität des Nachfrage nach Ersatzgütern. Zeitschrift für Nationalökonomie 1.1:51-74.

- 1933. Interrelation des prix et courbes statistiques de demande et d'offre Econometrica 1:162-71.

Ferger, W. F. 1932. The Static and the Dynamic in Statistical Demand Curves. Quarterly Journal of Economics 47:36-62.

Fisher, Irving. [1892] 1961. Mathematical Investigations in the Theory of Value and Prices. Reprint, New York: Kelley.

Friedman, Milton. 1934. The Fitting of Indifference Curves as a Method of Deriving Statistical Demand Curves. Manuscript. Milton Friedman's personal papers.

— 1949. The Marshallian Demand Curve. Journal of Political Economy 57:463-95. 
Gilboy, E. W. 1930. Demand Curves in Theory and Practice. Quarterly Journal of Economics 44:601-20.

- 1932. Studies in Demand: Milk and Butter. Quarterly Journal of Economics 46:671-97.

- 1934. Time Series and the Derivation of Demand and Supply Curves: A Study of Coffee and Tea, 1850-1930. Quarterly Journal of Economics 48:667-85.

Hands, Wade, and Philip Mirowski. 1998. Harold Hotelling and the Neoclassical Dream. In Economics and Methodology: Crossing Boundaries, edited by Roger E. Backhouse, Daniel Hausman, Uskali Mäki, and Andrea Salanti. London: Macmillan.

Hayek, Friedrich von. 1943. The Geometrical Representation of Complementarity. Review of Economic Studies 10.2:122-25.

Hicks, John. [1932] 1957. The Theory of Wages. Gloucester, Mass.: Peter Smith.

— 1933. IV_A Note on Mr. Kahn's Paper (Notes on Elasticity of Substitution). Review of Economic Studies 1.1:78-80.

—_ 1937. Théorie mathématique de la valeur en régime de libre concurrence. Paris: Hermann.

- 1939. Value and Capital. 2nd ed. Oxford: Clarendon.

- 1956a. A Revision of Demand Theory. Oxford: Clarendon.

- 1956b. Valeur et capital. Paris: Dunod.

- 1973. Recollections and Documents. Economica, n.s., 40.157:2-11.

1981. Wealth and Welfare: Collected Essays on Economic Theory. Vol. 1. Cambridge, Mass.: Harvard University Press.

— . [1979] 1983. The Formation of an Economist. In vol. 3 of Classics and Moderns: Collected Essays on Economic Theory. Cambridge, Mass.: Harvard University Press.

- 1983. Classics and Moderns: Collected Essays on Economic Theory. Vol. 3. Cambridge, Mass.: Harvard University Press.

Hicks, John R., and Roy G. D. Allen. 1934. A Reconsideration of the Theory of Value. Pts. 1 and 2. Economica, n.s., 1 (February): 52-76; 1 (May): 196-219.

Hotelling, Harold. 1932. Edgeworth's Taxation Paradox and the Nature of Demand and Supply Functions. Journal of Political Economy 40:577-616.

- 1933. Note on Edgeworth's Taxation Phenomenon and Professor Garver's Additional Condition on Demand Functions. Econometrica 1.4:408-9.

- 1935. Demand Functions with Limited Budgets. Econometrica 3:66-78.

1939. The Work of Henry Schultz. Econometrica 7:97-103.

Jevons, William Stanley. [1871] 1965. The Theory of Political Economy. Reprint, New York: Kelley.

Johnson, William Ernest. 1913. The Pure Theory of Utility Curves. Economic Journal 23:483-513. Reprinted in Baumol and Goldfeld 1968.

Knight, Frank. 1944. Realism and Relevance in the Theory of Demand. Journal of Political Economy 52:289-318.

Lange, Oskar. 1940. Complementarity and Interrelations of Shifts in Demand. Review of Economic Studies 18.1:58-63. 
Lehfeldt, R. A. 1914. The Elasticity of Demand for Wheat. Economic Journal 24:212-17.

- 1915. Review of Moore's Economic Cycles: Their Law and Cause. Economic Journal 25:409-11.

Lenfant, Jean-Sébastien. 2003. In Search of Complementarity. Paper presented at the HES conference, Durham, North Carolina, July.

Lewis, E. E. 1937. Note on Inter-commodity Relationships in Demand. Review of Economic Studies 5.1:53-59.

— 1938a. Intercommodity Relationships in Stable Demand. Econometrica 6:130-42.

- 1938b. The Relation of Commodities in Demand. American Economic Review 28.3:488-96.

Marschak, Jacob. 1943. Money, Illusion, and Demand Analysis. Review of Economics and Statistics 24:40-48.

Marshall, Alfred. [1890] 1898. Principles of Economics. 4th ed. London: Macmillan.

Mirowski, Philip. 1990. Problems in the Paternity of Econometrics: H. L. Moore. HOPE 22.4:587-609.

Mongin, Philippe. 1988. Le réalisme des hypothèses et la Partial Interpretation View. Philosophy of the Social Sciences 18:281-325.

- 2000. Les préférences révélées et la formation de la théorie du consommateur. Revue économique 51 (September): 1125-52.

Moore, Henry Ludwell. [1914] 1967. Economic Cycles: Their Law and Cause. Series: Reprints of economics classics. New York: A. M. Kelley.

— 1926. Partial Elasticity of Demand. Quarterly Journal of Economics 40:393401.

. [1917] 1967. Forecasting the Yield and the Price of Cotton. Reprint, New York: Kelley.

—_. [1929] 1967. Synthetic Economics. Reprint, New York: Kelley.

Morgan, Mary. 1990. The History of Econometric Ideas. Cambridge: Cambridge University Press.

Mosak, Jacob. 1938. Interrelations of Production, Price, and Derived Demand. Journal of Political Economy 46.6:761-87.

1942. On the Interpretation of the Fundamental Equation of Value Theory. In Studies in Mathematical Economics and Econometrics in Memory of Henry Schultz, edited by O. Lange, F. McIntyre, and T. O. Yntema. Chicago: University of Chicago Press.

Newman, Peter. 1987. Substitutes and Complements. In vol. 4 of Eatwell, Milgate, and Newman 1987.

Pareto, Vilfredo. [1909] 1971. Manuel d'économie politique. Paris: Giard et Brière.

Robinson, Joan. 1933. The Theory of Imperfect Competition. London: Macmillan.

Rosenstein-Rodan, Paul N. 1933. La complementarietà prima delle tre tappe del progresso della teoria economica pura. La riforma sociale 99:257-308.

Samuelson, Paul. 1938a. A Note on the Pure Theory of Consumer's Behaviour. Economica, n.s., 4.16:61-71. 
1938b. A Note on the Pure Theory of Consumer's Behaviour: An Addendum. Economica, n.s., 5.19:353-54.

1950. The Problem of Integrability in Utility Theory. Economica, n.s., 15

(November): 243-53.

- 1974. Complementarity: An Essay on the 40th Anniversary of the Hicks-Allen Revolution in Demand Theory. Journal of Economic Literature 12:1255-89.

Schultz, Henry. 1927. Mathematical Economics and the Quantitative Method. Journal of Political Economy 5.35:702-6.

_ 1928a. Rational Economics. American Economic Review 18:649-62.

1928b. The Statistical Laws of Demand and Supply, with Special Application to Sugar. Chicago: University of Chicago Press.

- 1931a. Henry L. Moore's Contributions to the Statistical Law of Demand. In Methods in Social Science, edited by Stuart A. Rice. Chicago: University of Chicago Press.

- 1931b. The Italian School of Mathematical Economics. Journal of Political Economy 39.1:76-85.

- 1933. Interrelations of Demand. Journal of Political Economy 41:468-512.

1935. Interrelations of Demand, Price, and Income. Journal of Political Economy 43:433-81.

- 1938. The Theory and Measurement of Demand. Chicago: University of Chicago Press.

Slutsky, Eugen. [1915] 1953. On the Theory of the Budget of the Consumer. In Readings in Price Theory, edited by K. E. Boulding and G. J. Stigler. London: Allen \& Unwin.

Stigler, George. 1954. The Early History of Empirical Studies of Consumer Behavior. Journal of Political Economy 62.2:95-113.

_ [ [1950] 1965. The Development of Utility Theory. In Essays in the History of Economics. Chicago: University of Chicago Press.

Tintner, Gerhard. 1938. The Theoretical Derivation of Dynamic Demand Curves. Econometrica 6:375-80.

Weber, Christian. 1999. More on Slutsky's Equation as Pareto's Solution. HOPE 31.3:575-86.

- 2000. Two Further Empirical Implications of Auspitz-Lieben-EdgeworthPareto Complementarity. Economic Letters 67:289-95.

Working, Elmer. 1927. What Do Statistical "Demand Curves" Show? Quarterly Journal of Economics 41.2:212-35.

Wright, Philip G. 1929. Statistical Laws of Demand and Supply. Journal of the American Statistical Association 24:207-15.

- 1930. Moore's "Synthetic Economics." Journal of Political Economy 38.3:328-44.

Wulwick, Nancy. 1995. A Reconstruction of Henry Moore's Demand Studies. In Measurement, Quantification, and Economic Analysis, edited by Ingrid Rima. London: Routledge.

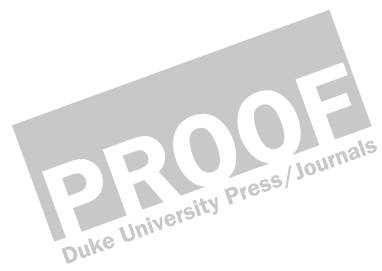

